\title{
Short Report: Establishing and sustaining a new interprofessional allied health student placement
}

\author{
W. Foley ${ }^{1,2}$, A. Fagan ${ }^{2}$ \& K. Liddle ${ }^{1}$
}

Keywords: student placement; interprofessional; allied health; speech pathology; occupational therapy; physiotherapy; Aboriginal and Torres Strait; primary health care.

\section{Introduction}

Meeting the increasing demand for allied health $(\mathrm{AH})$ clinical placements is challenging (McBride, Fitzgerald, Morrison, \& Hulcombe, 2015), as is providing experience for AH students in authentic interprofessional practice (Copley et al., 2007). Furthermore, limited opportunities exist to develop AH students' skills in working effectively with Indigenous clients (Hill, Nelson, Copley, Quinlan, \& White, 2017), due to the low number of health professionals practising in Indigenous communities (Nelson, Shannon, \& Carson, 2013; Whitford, Taylor, \& Thomas, 2013).

The need for paediatric AH services for developmentally-vulnerable children in the Inala Indigenous community was identified in 2014 by the Southern Queensland Centre of Excellence in Aboriginal and Torres Strait Islander Primary Health Care's $(\mathrm{CoE})$ visiting paediatrician. Children in the region are developmentally vulnerable in all domains, particularly in language and communication, where the average percentage of vulnerable children is twice that in the Queensland population and more than double the national figures (Commonwealth of Australia, 2015). In 2014, the demand for the local mainstream public child development service exceeded capacity, leading to lengthy waiting lists. With few nearby private $\mathrm{AH}$ practices offering paediatric services, many Inala paediatric patients were unable to access comprehensive $\mathrm{AH}$ assessments and care. At the time, no paediatric $\mathrm{AH}$ clinical services or training opportunities existed within the CoE.

1 Southern Queensland Centre of Excellence in Aboriginal and Torres Strait Islander Primary Health Care, Brisbane, Australia

2 The University of Queensland, Brisbane, Australia

\section{Correspondence}

Wendy Foley

Southern Queensland Centre of Excellence in Aboriginal and Torres Strait Islander Primary Health Care

37 Wirraway Parade

Brisbane, QLD 4077

Australia

Tel: +61 731014222

Email: wendy.foley@health.qld.gov.au 
Interprofessional student placements can help address service gaps (Frakes et al., 2014). In response to evident needs, a new student placement to provide services while training culturally-responsive clinicians (ClinEdAus, n.d.) was conceived. At the time of writing, this placement has continued for eight semesters, providing vital paediatric care previously unavailable within the hosting health service and an interprofessional placement within an Aboriginal and Torres Strait Islander (henceforth "Indigenous") setting for 81 students.

This paper aims to describe the process of establishing and sustaining this interprofessional placement for speech pathology (SP), physiotherapy (PT) and occupational therapy (OT) students in the CoE, in partnership with University of Queensland's School of Health and Rehabilitation Sciences (the "School"), and to highlight key factors enabling its sustainability.

\section{Innovation}

In 2014, the CoE approached the School regarding developing student-assisted AH paediatric services to fill the identified service gap. The School's SP and OT student clinics had developed effective interprofessional student-assisted services (Copley et al., 2007), in particular, with children in urban Indigenous service settings (Davidson, Hill, $\&$ Nelson, 2013), providing the model for the service described here.

Action stalled initially due to the lack of CoE SP, PT or OT staff or funding for sessional clinical educators (CEs) to supervise students; however, a 2015 Queensland Regional Training Network (QRTN) small grant to support increasing student placements was secured in mid-2015 and planning for a student clinic proceeded. The grant covered the cost of casual CE time for one semester and equipment and interview transcription for the evaluation research. The $\mathrm{CoE}$ and the School then collaborated to pilot and evaluate the clinic for one semester (August-October 2015).

With 5 weeks from receiving the grant to the new placement commencement, the nascent $\mathrm{CoE} / \mathrm{School}$ team acted swiftly. Formal agreements were established between QRTN and the CoE, and between the CoE and the School. Relationships between key $\mathrm{CoE}$ and School staff were established, logistics arranged and procedures for the new clinic designed and integrated within the CoE's services. A protocol for research to evaluate the acceptability of the clinic to all stakeholders in the first semester was developed, community support for the research obtained and ethics approval granted by the Metro South Human Research Ethics Committee and the UQ Human Research Ethics Committee. The coordinator, a CoE staff member with an education, allied health and research background, liaised between the $\mathrm{CoE}$ education, paediatric and administration staff and the School clinic managers to achieve these tasks. The coordinator also drove the research.

Meetings between the School clinic managers for each discipline, the coordinator and the CoE practice manager were held to discuss plans, logistics and the evaluation at the beginning and end of each semester. Weekly contact between the CEs, paediatrician and the $\mathrm{CoE}$ administration team was also facilitated by the coordinator to ensure smooth 
running of the clinic. Regular emails and phone contact regarding referrals, room and appointment bookings and case conferences constituted the main communication between these groups.

The service is a half-day clinic once per week during the university semester, initially with client referrals from the $\mathrm{CoE}$ paediatrician and paediatric registrars. Hourlong interprofessional appointments are supervised by CEs from the disciplines on placement. CEs also facilitate interactive collaborative sessions with students. One CE from each participating discipline supports the students each semester. The CEs, paediatrician, registrars, coordinator and administrators modelled collaborative practice and teamwork, essential elements for the students to observe and develop as part of their interprofessional practice skills. The students, CEs and paediatric team have several case conferences each semester, and the CEs provide outside clinic hours support for planning and documentation. The $\mathrm{CoE}$ provides administrative support for appointment-making and reminders. Academic timetables prevented constant student interprofessional (IP) pairs for the first 7 semesters, during which time, the SP students attended each week while OT and PT student cohorts changed once or twice. OT students were available in alternate semesters.

The clinic has evolved. In the eighth semester, IP student partners worked together for 8 weeks before replacement by a new IP pair.

\section{Research summary}

Research was planned to evaluate the acceptability of the student-assisted clinic to all stakeholders during its first semester and was extended for a second semester. It also contributed to development of the program. Qualitative methods were used, as they can answer questions about experience, meaning and perspective from the participants' standpoint (Hammarberg, Kirkman, \& de Lacey, 2016). Semi-structured interviews elicited experiences with and opinions about the clinic from parents/carers of the clients $(\mathrm{n}=14)$, referring paediatrician/registrars $(\mathrm{n}=3)$ and the CEs $(\mathrm{n}=4)$. All students ( $\mathrm{n}=15$ ) submitted weekly reflections, following guidelines, on cultural insights, IP collaboration and their clinical work. Written consent was obtained from each participant.

The research (to be published separately) demonstrated sustained client engagement due to improved access to needed therapy and parent/carer satisfaction with the outcomes for their children, including improved school participation and communication in school, home and social settings. Some parents reported improved understanding of their child's challenges and how to engage with their child constructively. They were satisfied with the students' professionalism and the access to the timely, publicly-funded support. The students, regardless of placement length, reported increasing confidence in their own professional skills and capacity to work with Indigenous clients, while learning about and from other professions and improving their communication skills. The CEs confirmed this. The paediatricians reported receiving positive feedback from families about the student clinic. They also reported that the student clinic 
complemented their work, the case conferences were helpful and the timeliness of the therapy was appreciated.

The positive results from the first semester evaluation (Foley et al., 2019) helped to support the paediatrician and coordinator's advocacy with the CoE management to fund the clinic for another semester. The research was continued for another semester, with ethics amendments made accordingly. At the end of the second semester, further evidence of positive outcomes supported advocacy with the $\mathrm{CoE}$ management and resulted in ongoing clinic funding.

\section{Evaluation}

The student-assisted clinic has evolved and grown over eight semesters, doubling student and client (aged 2 to 16 years) numbers and almost tripling the occasions of service (Table 1).

Table 1

Student and Client Participation in the Clinic, by Semester

\begin{tabular}{|c|c|c|c|c|c|}
\hline $\begin{array}{l}\text { Semester, } \\
\text { Year }\end{array}$ & $\begin{array}{l}\text { Student numbers } \\
\text { each week }\end{array}$ & $\begin{array}{l}\text { Student numbers } \\
\text { by discipline }\end{array}$ & $\begin{array}{c}\text { Number of } \\
\text { case } \\
\text { conferences }\end{array}$ & $\begin{array}{l}\text { Number of } \\
\text { children } \\
\text { participating }\end{array}$ & $\begin{array}{l}\text { Occasions of } \\
\text { service } \\
\text { attended }\end{array}$ \\
\hline 2,2015 & 4 & $\begin{array}{r}\text { SP-2 } \\
* \text { OT-4 }\end{array}$ & 1 & 9 & 36 \\
\hline 1,2016 & 5 & $\begin{array}{r}\text { SP-3 } \\
+ \text { PT-6 }\end{array}$ & 5 & 12 & 63 \\
\hline 2,2016 & 8 & $\begin{array}{r}\text { SP-4 } \\
* \text { OT-8 }\end{array}$ & 4 & 10 & 53 \\
\hline 1,2017 & 5 & $\begin{array}{r}\text { SP-3 } \\
+ \text { PT-6 }\end{array}$ & 4 & 10 & 57 \\
\hline 2,2017 & $\begin{array}{c}9 \text { (weeks 1-8) } \\
5 \text { (weeks 9-11)\# }\end{array}$ & $\begin{aligned} & \text { SP-3 } \\
* & \text { OT-4 } \\
+ & \text { PT-6 }\end{aligned}$ & 4 & 16 & 91 \\
\hline 1, 2018 & 6 & $\begin{array}{r}\text { SP-4 } \\
+ \text { PT-6 }\end{array}$ & 3 & 14 & 59 \\
\hline 2,2018 & 8 & $\begin{aligned} & \text { SP-4 } \\
&{ }^{*} \text { OT-4 } \\
&+ \text { PT-6 }\end{aligned}$ & 4 & 17 & 98 \\
\hline 1,2019 & 4 & $\begin{array}{l}{ }^{*} \mathrm{SP}-4 \\
{ }^{*} \mathrm{OT}-4\end{array}$ & 3 & 24 & 91 \\
\hline Total & & 81 & 28 & $\begin{array}{l}\text { Some children } \\
\text { attended several } \\
\text { semesters so total } \\
\text { is not indicative }\end{array}$ & 548 \\
\hline
\end{tabular}

\section{Note:}

$\mathrm{SP}=$ speech pathology; OT = occupational therapy; $\mathrm{PT}$ = physiotherapy

The complexity of changing student cohorts by discipline is shown in the table:

* two sequential student groups over the semester

+ three sequential student groups over the semester

\# Weeks 1-8: 3 SP, 4 OT, 2 PT students; Weeks 9-11: 3 SP \& 2 PT students 
The initial research and the ongoing engagement of children in the clinic indicates that the clinic is meeting community needs. Referrals from CoE GPs, child health nurses and some external agencies also indicate that the clinic is of value. The clinic is now managing a growing waiting list.

\section{Challenges}

The clinic has been located in less than ideal spaces. In the first year, the rooms in the community health centre across the road from the CoE's clinic were not child-friendly; from the third to the fifth semester, although the clinic was in child-friendly rooms in the community health centre, it was, again, away from the CoE; in the sixth semester, the clinic moved to the CoE's new building, for the first time providing direct access to $\mathrm{CoE}$ receptionists, culturally-safe space and the practice software, but it was split between three different areas in the CoE, so the space was not ideal. In the eighth semester, the clinic was finally located all together in an ideal paediatric space.

The non-alignment of the different disciplines' placement durations also presented a challenge. The initial rushed establishment of working relationships between the $\mathrm{CoE}$ and the School stakeholders resulted in some things being unsaid and unplanned. The changing of student cohorts, for example, was a surprise to the $\mathrm{CoE}$ in the first semester. Over time, with improved communication between the School and CoE, strategies were developed to deal with the student changes during semesters in a way that maintained cultural safety for clients and enhanced cultural competency for the new students. The CEs and the outgoing students engage in a hand-over process with the new students to enable smooth transitions, while the continuing students and CEs safeguard continuity of care for the clients.

\section{Sustainability factors}

Several factors contributed to the sustainability of this student-assisted interprofessional placement. Chief among these were the determination to provide students with meaningful work experience while also providing needed services in the $\mathrm{CoE}$ and the flexibility to make the most of available resources rather than waiting for perfect circumstances. Without determination and flexibility, it would have been easy to give up when the funding was inadequate and the available spaces not ideal; however, with collaborative effort, the team overcame these challenges, identifying funding opportunities and using available rooms while striving to keep improving the placement.

Hill et al. (2017) identified key contributors to developing student placements in Indigenous settings, including structures and processes, and relationships. In the example presented in this article, coordination was a vital process, ensuring adaptation to new spaces, processes, disciplines and students. The coordinator liaises between the CoE, School and other stakeholders to renegotiate agreements each semester, advocate for the student clinic needs within the CoE, organise service and community orientation for new students, and support team meetings, case conferences and the weekly clinic as necessary. Developing and maintaining the team is also incorporated into the coordinator's role, 
which contributes to the clinic's sustainability. Robust team relationships also contribute to the sustainability of the clinic. Communication via meetings and email between the institutions keeps the clinic running smoothly and strengthens our working relationships. After eight semesters, there is good understanding between the CoE and the School, facilitated by low staff turnover during the time. Negotiations became easier as trust and mutual understanding increased. Initially, there was some focus on who pays for what and haggling over contractual arrangements. When deciding what disciplines would be available, for example, questions arose about whose needs we were prioritising $(\mathrm{CoE}$ or School; clients or students). The goal is to meet the needs of all these stakeholders. Open communication between the stakeholders and a focus on the outcomes for both students and clients has been vital. Each semester, as new challenges arise, the team works in partnership to improve the placement opportunity.

The experiences in establishing and sustaining this interprofessional $\mathrm{AH}$ student placement support the conclusion of McBride et al. (2015) that placement capacity can be increased when value is placed on clinical education and investment is made in its support. The CoE made investments in sessional $\mathrm{CE}$ time and staff time for conducting the evaluation, ongoing coordination and administration support. To sustain this placement, these investments were essential. Investments in building and maintaining institutional relationships between the $\mathrm{CoE}$ and the School were also important. Embedding research into the placement's establishment was instrumental in influencing its sustainability. Without having data to demonstrate the acceptability of the student-assisted clinic to clients, the School and the paediatrician, the investments may not have continued.

\section{Conclusion}

There are, indeed, challenges to meet the growing need for clinical placements (McBride et al., 2015). The approach described in this article demonstrates growing student placement capacity while also meeting unmet service needs. With determination, flexibility and investment in coordination and research, together with an emphasis on building a strong relationship between the university and health service, new student placements can be generated and sustained.

\section{What Next?}

With the semester-length student-assisted AH therapy services now a routine part of the paediatric health service of the $\mathrm{CoE}$, the student-assisted service will continue to evolve with the $\mathrm{CoE}$ and the School. We aspire to embed it as a full-day year-round service, with dedicated $\mathrm{AH}$ practitioners to support student placements and meet the needs now evident in the community. 


\section{References}

ClinEdAus. (n.d.). Benefits of Indigenous placements. Retrieved from http://www. clinedaus.org.au/topics-category/benefits-of-indigenous-placements-60

Commonwealth of Australia. (2015). Australian early development census. Retrieved from https://www.aedc.gov.au/

Copley, J., Allison, H., Hill, A., Moran, M., Tait, J., \& Day, T. (2007). Making interprofessional education real: A university clinic model. Australian Health Review, 31(3), 351-357.

Davidson, B., Hill, A. E., \& Nelson, A. (2013). Responding to the World Report on Disability in Australia: Lessons from collaboration in an urban Aboriginal and Torres Strait Islander school. International Journal of Speech-Language Pathology, 15(1), 69-74. doi:10.3109/17549507.2012.732116

Frakes, K.-A., Brownie, S., Davies, L., Thomas, J., Miller, M.-E., \& Tyack, Z. (2014). Experiences from an interprofessional student-assisted chronic disease clinic. Journal of Interprofessional Care, 28(6), 573-575. doi:10.3109/13561820.2014.91 7404

Hammarberg, K., Kirkman, M., \& de Lacey, S. (2016). Qualitative research methods: When to use them and how to judge them. Human Reproduction, 31(3), 498-501. doi:10.1093/humrep/dev334

Hill, A. E., Nelson, A., Copley, J., Quinlan, T., \& White, R. (2017). Development of student clinics in Indigenous contexts: What works? Journal of Clinical Practice in Speech-Language Pathology, 19(1), 40-45.

McBride, L.-J., Fitzgerald, C., Morrison, L., \& Hulcombe, J. (2015). Pre-entry student clinical placement demand: Can it be met? Australian Health Review, 39(5), 577-581. doi:10.1071/AH14156

Nelson, A., Shannon, C., \& Carson, A. (2013). Developing health student placements in partnerships with urban Aboriginal and Torres Strait Islander community controlled health services. In Leaders in Indigenous Medical Education Network, LIME Good Practice Case Studies, Vol. 2. (pp. 29-34). Parkville, Victoria: Onemda VicHealth Koori Health Unit, The University of Melbourne.

Whitford, D., Taylor, J., \& Thomas, K. (2013). Working in Indigenous health settings. In K. Stagnitti, A. Schoo, \& D. Welch (Eds.), Clinical and fieldwork placement in the health professions (pp. 329-347). Melbourne, Australia: Oxford University Press Australia and New Zealand. 